\title{
Oxygen Electrode Kinetics and Surface Composition of Dense (La0.75Sr0.25)0.95MnO3
} on YSZ

Wu, Yuehua; Hansen, Karin Vels; Norrman, Kion; Jacobsen, Torben; Mogensen, Mogens Bjerg

Published in:

E C S Transactions

Link to article, DOI:

$10.1149 / 05701.1673$ ecst

Publication date:

2013

Document Version

Publisher's PDF, also known as Version of record

Link back to DTU Orbit

Citation (APA):

Wu, Y., Hansen, K. V., Norrman, K., Jacobsen, T., \& Mogensen, M. B. (2013). Oxygen Electrode Kinetics and Surface Composition of Dense ( $\left.\mathrm{La}_{2} \mathrm{Sr}_{0.25}\right)_{0.95} \mathrm{MnO}_{3}$ on YSZ. E C S Transactions, 57(1), 1673-1682.

\section{General rights}

Copyright and moral rights for the publications made accessible in the public portal are retained by the authors and/or other copyright owners and it is a condition of accessing publications that users recognise and abide by the legal requirements associated with these rights.

- Users may download and print one copy of any publication from the public portal for the purpose of private study or research.

- You may not further distribute the material or use it for any profit-making activity or commercial gain

- You may freely distribute the URL identifying the publication in the public portal 
ECS Transactions, 57 (1) 1673-1682 (2013)

10.1149/05701.1673ecst @The Electrochemical Society

\title{
Oxygen Electrode Kinetics and Surface Composition of Dense $\left(\mathrm{La}_{0.75} \mathrm{Sr}_{0.25}\right)_{0.95} \mathrm{MnO}_{3}$ on YSZ
}

\author{
Yuehua $\mathrm{Wu}^{\mathrm{a}}$, Karin Vels Hansen ${ }^{\mathrm{a}}$, Kion Norrman ${ }^{\mathrm{a}}$, \\ Torben Jacobsen ${ }^{\mathrm{a}}$, Mogens Bjerg Mogensen ${ }^{\mathrm{a}}$ \\ ${ }^{a}$ Department of Energy Conversion and Storage, Technical University of Denmark, \\ Frederiksborgvej 399, Roskilde, DK-4000 Roskilde, Denmark
}

\begin{abstract}
Lanthanum strontium manganate (LSM) micro-electrodes with the nominal composition of $\left(\mathrm{La}_{0.75} \mathrm{Sr}_{0.25}\right)_{0.95} \mathrm{MnO}_{3}$ were deposited on yttria stabilized zirconia (YSZ). The diameter varied from $20-$ $100 \mu \mathrm{m}$ and the thickness was kept constant at ca. $0.5 \mu \mathrm{m}$. Electrochemical characterization was carried out in situ at temperatures from 660 to $860{ }^{\circ} \mathrm{C}$ using a controlled atmosphere high temperature scanning probe microscope (CAHT-SPM) setup for measurements of impedance spectroscopy and potential sweep. The oxygen partial pressure, $p \mathrm{O}_{2}$, was varied. Further, ex situ surface analysis by time of flight secondary ion mass spectrometry (TOF-SIMS) and structure examination by scanning electron microscopy (SEM) were performed. Segregation of $\mathrm{Sr}$ and La oxides to LSM surfaces and Mn rich oxide to the three phase boundary (TPB) was observed. YSZ and LSM attract different oxides/impurities. The oxygen electrode kinetics are discussed in light of the surface compositions and compared with the literature on microelectrode and composite LSM-YSZ electrode kinetics.
\end{abstract}

\section{Introduction}

There has been quite a number of research works carried out on oxygen reduction reaction kinetics on LSM microelectrodes with well-defined geometry. Brichzin et al. (1) studied the dependence on diameter and thickness of the polarization resistance of LSM microelectrodes on YSZ. Circular LSM microelectrodes with diameters ranging from 10 to $500 \mu \mathrm{m}$ and nominal thickness of $100-800 \mathrm{~nm}$ were prepared by pulsed laser deposition (PLD) and photolithography. The electrical characteristics of the LSM microelectrodes were characterized by impedance spectroscopy and $\mathrm{i}-\mathrm{V}$ measurements at $800{ }^{\circ} \mathrm{C}$ in air. The slope of the electrode polarization resistance $\left(R_{p}\right)$ versus the microelectrode diameter in a double-logarithmic plot was determined at different polarization values. The slope was around -2 in the cathodic regime, indicating that the electrode polarization resistance is proportional to the microelectrode area. In the anodic region, the slope was approaching -1 , indicating that $R_{p}$ has linear relation with the TPB length. The LSM composition was not mentioned in their study. Later Fleig et al. (2) further studied partial pressure dependence of the polarization resistance of LSM microelectrodes on YSZ. $\left(\mathrm{La}_{0.8} \mathrm{Sr}_{0.2}\right)_{0.92} \mathrm{MnO}_{3}$ microelectrodes, with diameters ranging from $20-100 \mu \mathrm{m}$ and thicknesses of 100 or $250 \mathrm{~nm}$, were prepared on polished 9.5YSZ single crystals and characterized at $800{ }^{\circ} \mathrm{C}$ in 4 different atmospheres, with $\mathrm{pO}_{2}$ ranging 
from $2 \times 10^{-4}$ bar to 1 bar. The determined slopes were between -2.05 and -2.51 . They concluded that the total polarization resistance consists of contributions from oxygen exchange on the LSM surface and ion transport through the LSM electrode. The oxygen exchange resistance decreases with increasing $\mathrm{pO}_{2}$ while the transport resistance increases with increasing $\mathrm{pO}_{2}$. Accordingly the rate-limiting step of the oxygen reduction reaction depends on the partial pressure with the surface resistance being limiting for low $p \mathrm{O}_{2}$ and ion transport for high $p \mathrm{O}_{2}$. la $\mathrm{O}^{\prime}$ et al. $(3,4)$ studied thickness dependence of the polarization resistance of LSM microelectrodes. They concluded that the surface oxygen exchange and mixed bulk/TPB charge transfer process control oxygen reduction reaction kinetics at high and low temperatures, respectively. In the present work, we investigate the influence of both $p \mathrm{O}_{2}$ and polarization on the electrical characteristics as well as the development of surface compositions of the LSM microelectrodes.

\section{Experimental}

\section{Preparation of LSM Microelectrodes on 8YSZ}

One side polished polycrystalline $8 \mathrm{YSZ}$ ( $8 \mathrm{~mol} \%$ yttria stabilized zirconia) pellets were chosen as the substrate. The $8 Y S Z$ pellets were sintered at $1500{ }^{\circ} \mathrm{C}$ in air for 2 hours. A diameter of $10 \mathrm{~mm}$ was obtained after sintering. The pellet surface was further polished. The LSM film was applied by PLD. The LSM target used for the deposition had a nominal composition of $\left(\mathrm{La}_{0.75} \mathrm{Sr}_{0.25}\right)_{0.95} \mathrm{MnO}_{3}$ and was sintered at $1200{ }^{\circ} \mathrm{C}$ in air for 2 hours. Prior to the deposition, the $8 Y S Z$ substrate was heated to $650{ }^{\circ} \mathrm{C}$ with a rate of $10{ }^{\circ} \mathrm{C}$ per minute under vacuum conditions $\left(1 \times 10^{-6} \mathrm{mbar}\right)$. The deposition took place at a substrate temperature of $650{ }^{\circ} \mathrm{C}$, a repetition rate of $15 \mathrm{~Hz}$, a target-substrate distance of $5.5 \mathrm{~cm}$, and a laser fluence of $4 \mathrm{~J} \mathrm{~cm}^{-2}$. The thickness of the LSM film (Figure 1 left) was measured by a Dektak profilometer (V200-Si, Veeco) to around $500 \mathrm{~nm}$. SEM of the cross-section of the LSM film (Figure 1 right) shows that the deposited film is dense and gas tight.
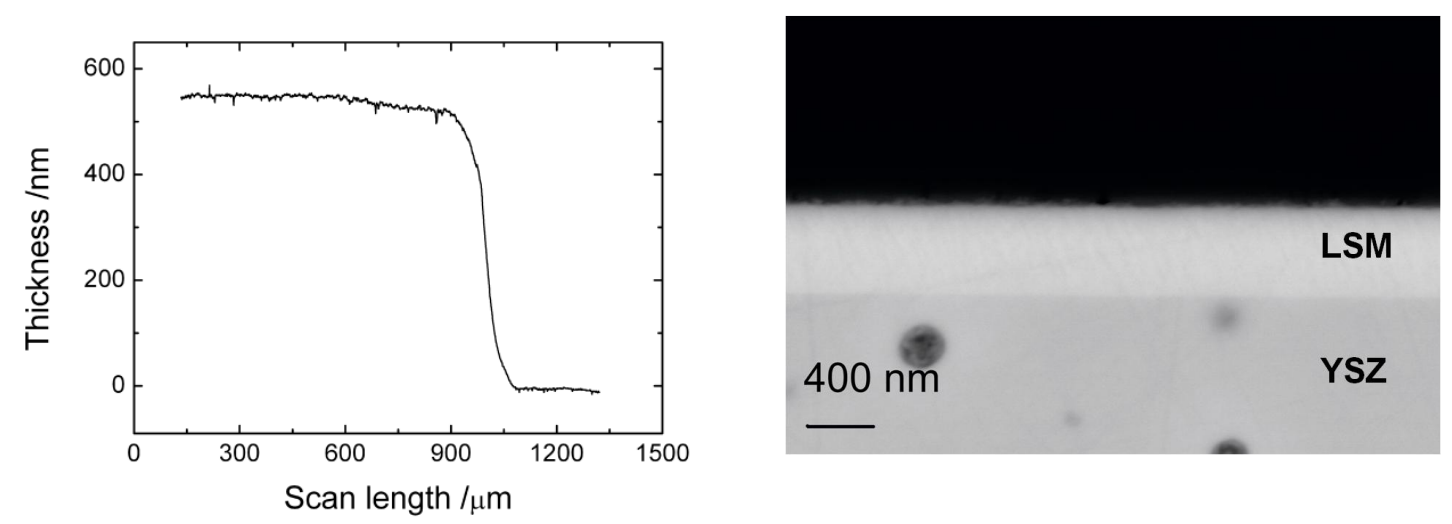

Figure 1. Left: thickness of LSM layer made by PLD as measured by a Dektak profilometer. Right: SEM image of the cross-section of an LSM film.

The LSM microelectrodes were shaped by a photolithography technique (5). After etching, differently sized circular LSM microelectrodes were left on the 8YSZ substrate. The LSM microelectrodes (and the substrate) were further annealed at $1000{ }^{\circ} \mathrm{C}$ in air for 
5 hours. The sizes of the microelectrodes were measured by optical microscopy, and they were further characterized by SEM, AFM (atomic force microscopy) and XRD (X-ray diffractometry). Figure 2 shows a SEM micrograph, and Figure 3 presents AFM images showing the surface morphology of a $50 \mu \mathrm{m}$ diameter LSM microelectrode. The LSM microelectrode is composed of small grains with grain sizes of $100-400 \mathrm{~nm}$. The LSM film is directly after PLD deposition composed of much smaller grains with a size of less than $100 \mathrm{~nm}$ (not shown). So during the annealing step some grain growth took place. The XRD measurement showed only peaks corresponding to YSZ and LSM. The LSM phase was well crystallized.

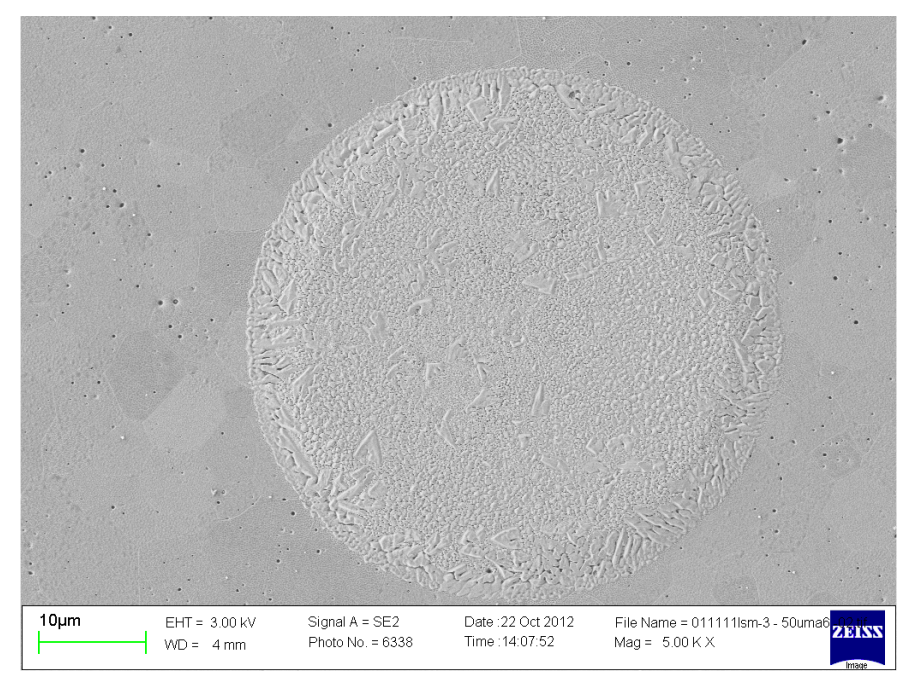

Figure 2. SEM of a $50 \mu \mathrm{m}$ diameter LSM microelectrode.
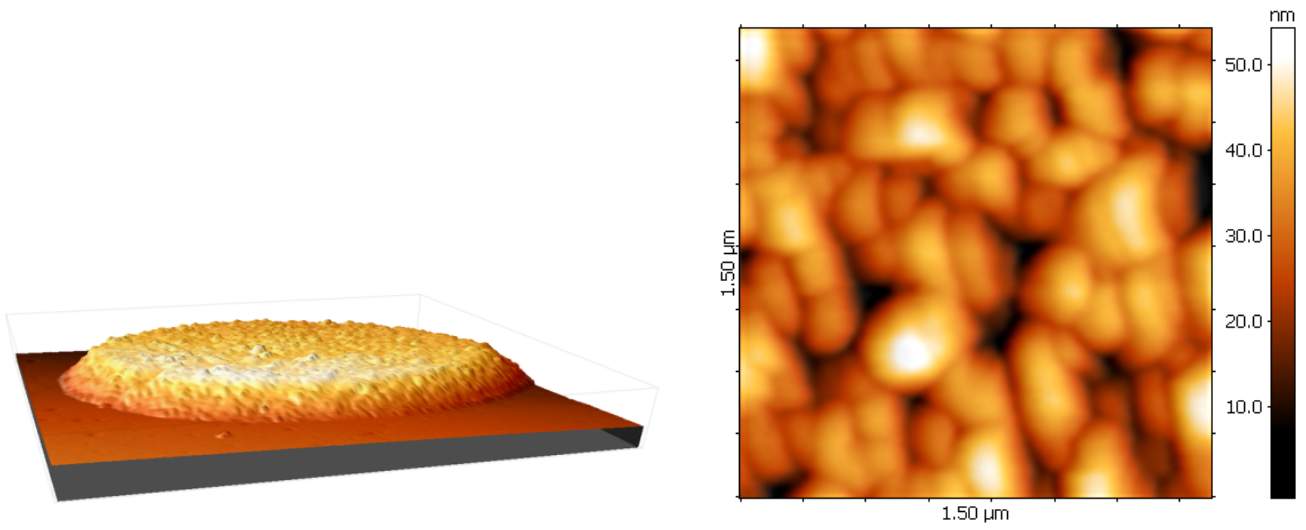

Figure 3. AFM images showing overview (left) and surface morphology (right) of a 50 $\mu \mathrm{m}$ diameter and $0.5 \mu \mathrm{m}$ thick LSM microelectrode.

The images seem to confirm the conclusion based on the SEM of the cross-section (Figure 1 right) that the LSM microelectrodes are dense. They have a surface roughness that in plane is of the order of few grain sizes, i.e. up to $0.5 \mu \mathrm{m} \times 0.5 \mu \mathrm{m}$, and up to 50 $\mathrm{nm}$ in height. The edges of the microelectrodes are sloping down to the YSZ over a length of 3-4 $\mu \mathrm{m}$. 


\section{Electrochemical Characterization}

The electrochemical measurements were carried out using a CAHT-SPM (DME Danish Micro Engineering A/S, Denmark). The CAHT-SPM is described in details elsewhere (6). It includes an AFM, an impedance measurement system and a temperature control system. The sample is placed on a heated stage. The sample temperature was measured by a thermocouple placed on the sample surface with an error of $\pm 15^{\circ} \mathrm{C}$. A conductive probe, made from $\mathrm{Pt}_{0.8} \mathrm{Ir}_{0.2}$ alloy, is used to contact selected LSM microelectrodes. The electrical characteristics of the LSM microelectrodes were determined by impedance spectroscopy under polarization and by measuring current density, i, as a function of applied voltage, V (i-V curves). Further experimental details on probe fabrication and electrochemical measurements have been presented elsewhere (7).

\section{Results}

$\underline{\text { Impedance at Open Circuit Voltage (OCV) }}$

Figure 4 (left) shows impedance spectra of a $50 \mu \mathrm{m}$ diameter LSM microelectrode measured at different temperatures in air. The impedance spectra were fitted with an equivalent circuit model that consists of a resistor, $R_{s}$, in serial connection with 4 parallel $R Q s$, where $R$ denotes resistor and $Q$ denotes a constant phase angle element in order to find the $R_{s}$ and $R_{p}$ as accurate as possible.

The intercept of the impedance spectrum with the $\mathrm{X}$-axis at high frequency reflects the ohmic resistance of the circuit, which in turn is approximately equal to the YSZ electrolyte resistance. As seen in Figure $4, R_{s}$ is very small compared to $R_{p}$, the total polarization resistance, which is the difference of the low and high frequency intercepts of the x-axis. The relationship between the electrolyte resistance, $R_{s}$, and the ionic conductivity of YSZ, $\sigma$, beneath a small circular electrode can be theoretically described with the Newman formula (8-10):

$$
R_{s}=1 /\left(2 \cdot d \cdot \sigma_{y s z}\right) \text { or } \sigma_{y s z}=1 /\left(2 \cdot d \cdot R_{s}\right)
$$

where $\mathrm{d}$ is the diameter of the microelectrode. As a check of the functionality of the whole set-up the ionic conductivity of $8 \mathrm{YSZ}$ was then derived based on the measured $R_{S}$ and was found to between $9.3 \times 10^{-3}$ and $5.1 \times 10^{-2} \mathrm{~S} / \mathrm{cm}$, and an activation energy for the ionic conduction of $8 Y \mathrm{YZ}$ of $0.86 \pm 0.03 \mathrm{eV}$ in the temperature range of $663-856{ }^{\circ} \mathrm{C}$ is in good agreement with literature values (11-13).

Figure 4 (right) gives $\ln \left(R_{p}\right)$, i.e. $R_{p}$ of the $50 \mu \mathrm{m}$ diameter LSM microelectrode derived by equivalent circuit fitting of the measured impedance spectra, against the inverse of the temperature. An activation energy of $1.82 \pm 0.03 \mathrm{eV}$ was obtained from linear regression. Previously Takeda et al. have reported an activation energy of $1.87 \mathrm{eV}$ for LSM $\left(\mathrm{La}_{0.7} \mathrm{Sr}_{0.3} \mathrm{MnO}_{3}\right.$ and $\left.\mathrm{La}_{0.5} \mathrm{Sr}_{0.5} \mathrm{MnO}_{3}\right)$ thin film electrodes deposited on YSZ (14). Later Siebert et al. studied $\mathrm{La}_{0.9} \mathrm{Sr}_{0.1} \mathrm{MnO}_{3}$ deposited on YSZ and derived the activation energy of electrode polarization resistance per unit surface area or unit perimeter length of $1.8-1.9 \mathrm{eV}(15)$. Thus, the activation energy determined from the present work is in good agreement with the values reported in the literature. 

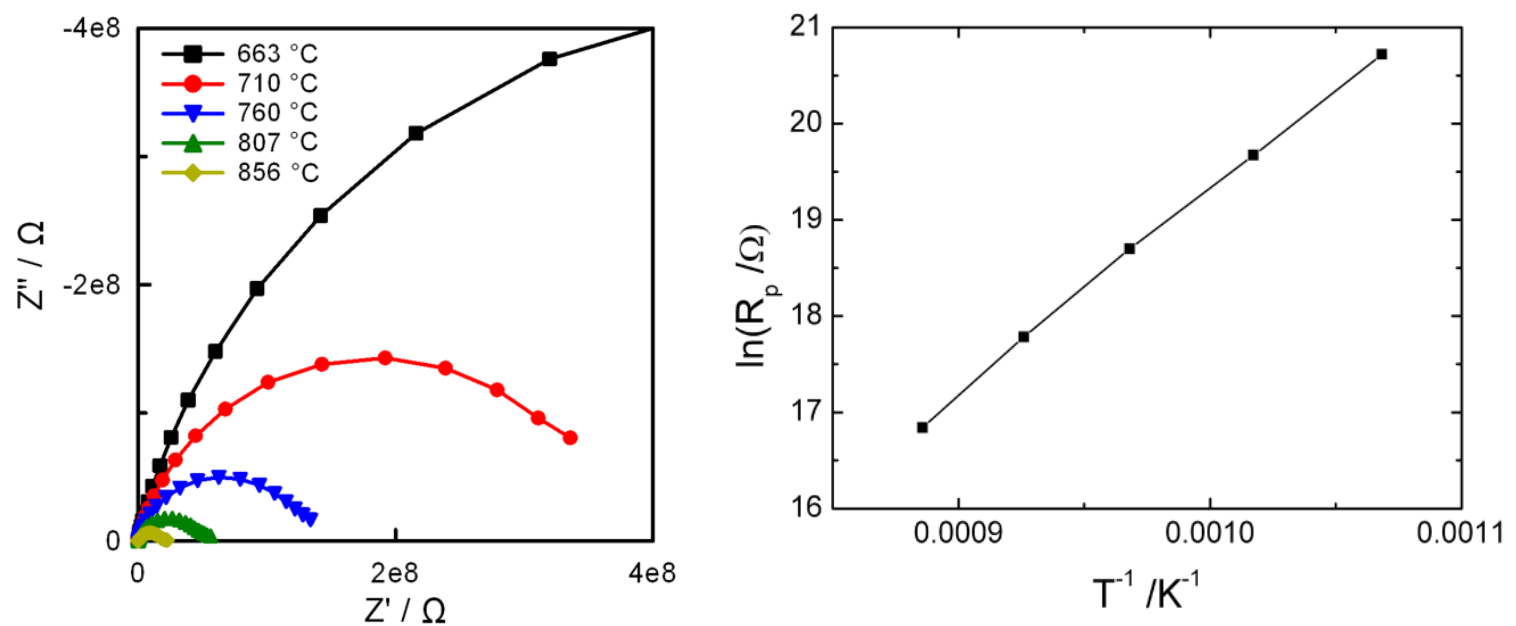

Figure 4. Left: impedance spectra of a $50 \mu \mathrm{m}$ diameter LSM microelectrode measured at different temperatures in air. Right: Arrhenius plot of the $R_{p}$ values derived from fitting the spectra in the left figure. The activation energy was calculated as $1.82 \pm 0.03 \mathrm{eV}$.
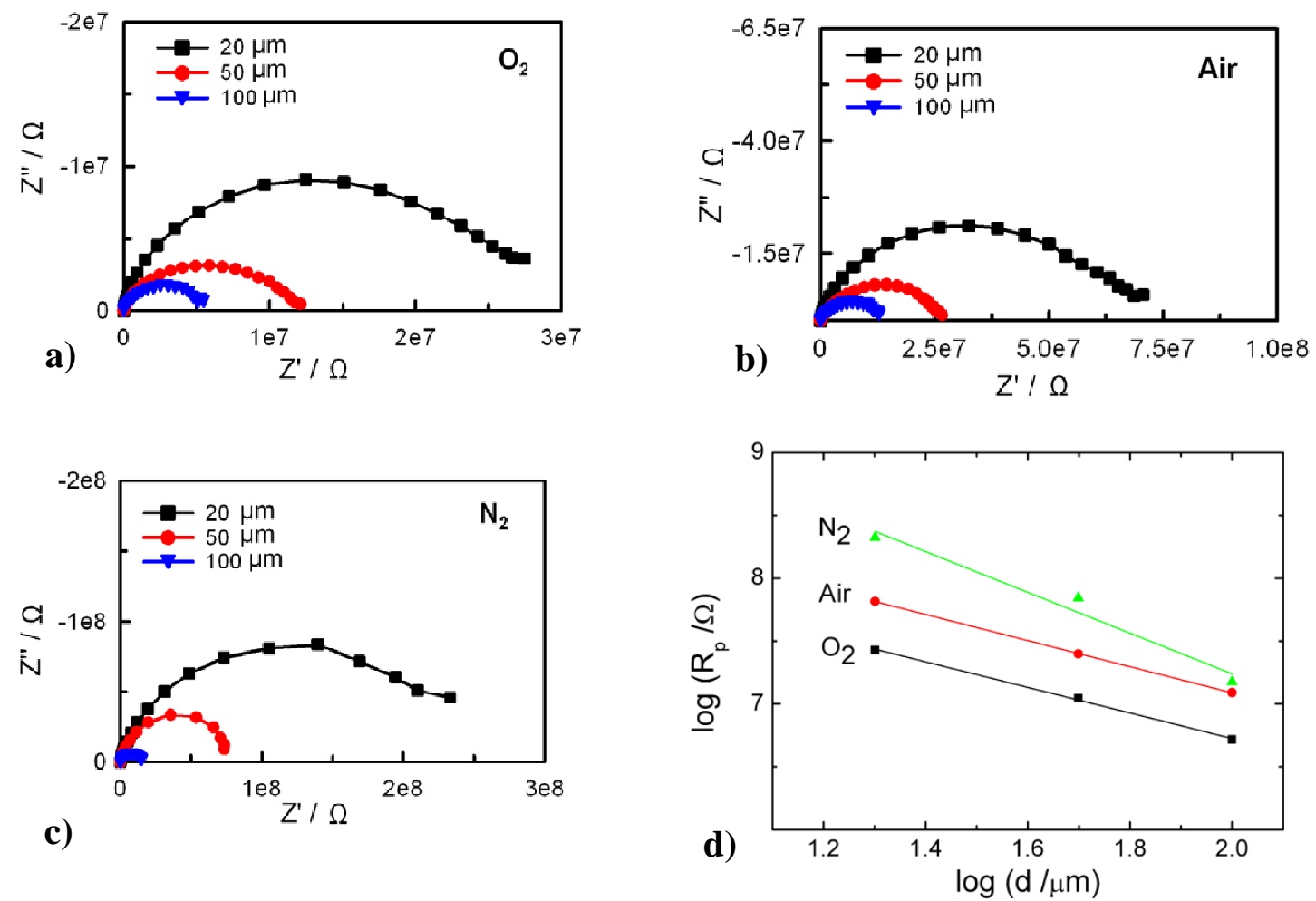

Figure 5. Impedance spectra of LSM microelectrodes measured at $\mathrm{OCV}$ at $856{ }^{\circ} \mathrm{C}$ in a) pure oxygen, b) air and c) $\mathrm{N}_{2}$, and d) a double-logarithmic plot of the electrode polarization resistance $\left(R_{p}\right)$ versus the microelectrode diameter, d, derived from the shown impedance spectra. The slopes obtained by linear regression are $-1.02 \pm$ $0.04,-1.04 \pm 0.00$, and $-1.62 \pm 0.28$ in pure $\mathrm{O}_{2}$, air and $\mathrm{N}_{2}\left(p \mathrm{O}_{2} \approx 10^{-4}\right.$ bar $)$, respectively. 
Figure 5 a), b) and c) show impedance spectra of differently sized LSM microelectrodes measured at $856{ }^{\circ} \mathrm{C}$ in pure oxygen, air, and $\mathrm{N}_{2}\left(p \mathrm{O}_{2}: 1\right.$ bar, 0.21 bar and ca. $1 \times 10^{-4}$ bar), and Figure $5 \mathrm{~d}$ ) shows a double-logarithmic plot of the electrode polarization resistance determined from impedance fitting versus the microelectrode diameter.

The slopes obtained by linear regression are close to 1 in air and pure oxygen, indicating that the polarization resistance scales with the inverse of the microelectrode diameter, i.e. with the length of the TPB. In $\mathrm{N}_{2}$, the slope is about -1.62 , indicating that the polarization resistance is related to the inverse of the electrode area, though not completely.

\section{$\underline{\text { Impedance under Polarization }}$}

In order to check how the electrical characteristics of the LSM microelectrodes are influenced by the current, impedance measurements were carried out on $50 \mu \mathrm{m}$ diameter LSM microelectrodes at $856{ }^{\circ} \mathrm{C}$ in pure oxygen under polarization. Figure 6 shows measured impedance spectra. The electrode polarization resistance decreases under cathodic as well as anodic polarization. The impedance spectra measured under cathodic polarization look similar to those at OCV (Figure 5). The impedance spectra under anodic polarization are different, especially for the low frequency part. The calculated areaspecific capacitance is in the order of $100 \mu \mathrm{F} \mathrm{cm}$ and $1 \mathrm{mF} \mathrm{cm}^{-2}$ for the high and low frequency arc, respectively. The low frequency arc shrinks significantly with increasing polarization. Under high anodic polarization $(350 \mathrm{mV}$, Figure 6 right), an inductive contribution is clearly visible. Similar phenomena have been observed by other groups $(15,16)$.
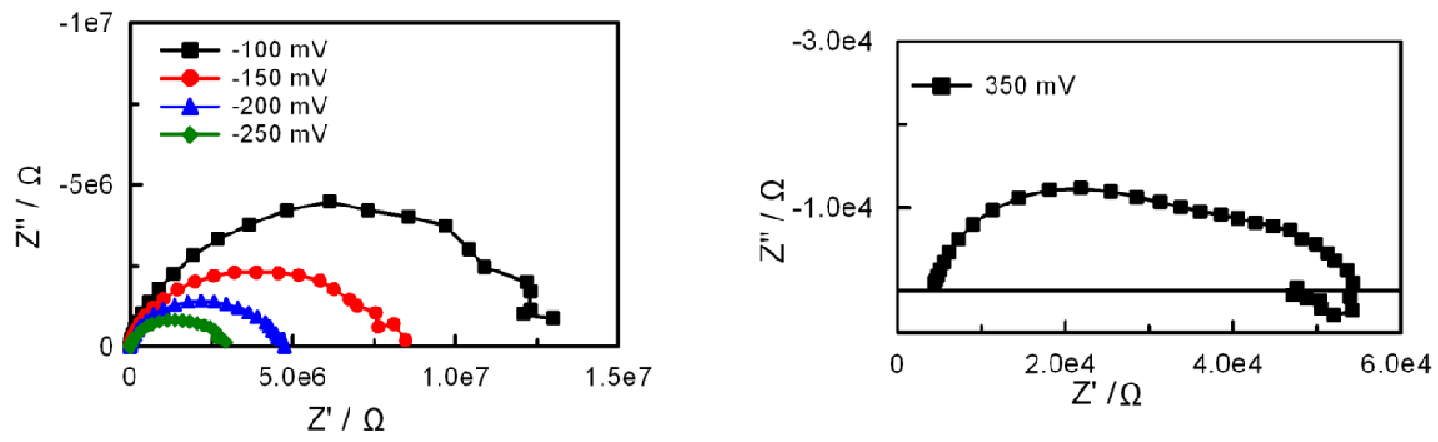

Figure 6. Impedance spectra of $50 \mu \mathrm{m}$ diameter LSM microelectrodes measured under polarization at $856{ }^{\circ} \mathrm{C}$ in pure oxygen. Left: cathodic polarization. Right: anodic polarization. Note the different scales.

\section{$\underline{\text { i - V Measurements }}$}

In addition $\mathrm{i}-\mathrm{V}$ measurements were conducted on differently sized microelectrodes. Figure 7 gives the slopes of the i-V curves measured on LSM microelectrodes with diameters ranging from 20 to $100 \mu \mathrm{m}$ at $856^{\circ} \mathrm{C}$ in $\mathrm{N}_{2}\left(p \mathrm{O}_{2} \approx 10^{-4}\right.$ bar $)$. 


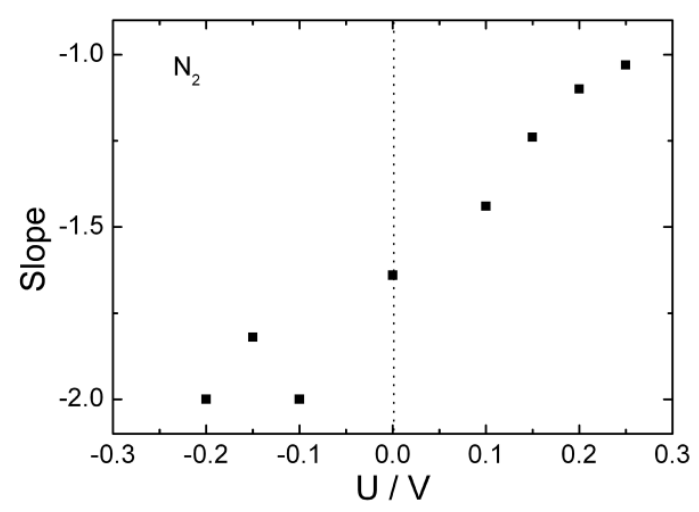

Figure 7. Geometry dependence of polarization resistance at different polarizations in $\mathrm{N}_{2}$ with $p \mathrm{O}_{2} \approx 10^{-4}$ bar. The slopes of double-logarithmic plots of $\log \left(R_{p}\right)$ versus $\log (d)$ (like in Figure $\left.5 \mathrm{~d}\right)$ ) are plotted as a function of electrode polarization. $R_{p}$ is here calculated from $\mathrm{i}-\mathrm{V}$ curves as the differential resistance.

Each scan was from 0 to $-350 \mathrm{mV}$ polarization, then to an anodic polarization of 350 $\mathrm{mV}$ and finally back to OCV. This was repeated three times. Differential polarization resistance, $R_{p}$, corresponding to $R_{p}$ determined by impedance spectroscopy at a given applied voltage was calculated from the slope of the $\mathrm{i}-\mathrm{V}$ curves after correction for the voltage drop due to the ohmic resistance, $\mathrm{i} \cdot R_{s}$. These resistances were then plotted in double-logarithmic plots versus the microelectrode diameter and the slope was calculated for specific polarization values. The slope at OCV was -1.64 in $\mathrm{N}_{2}$ with $p \mathrm{O}_{2} \approx 10^{-4}$ bar, similar to the values obtained from the impedance measurements (Figure 5). There is a clear dependence between the slope and the applied polarization, being close to -1 at 250 $\mathrm{mV}$ (anodic) and -2 at $-200 \mathrm{mV}$ (cathodic) and changing continuously in-between.

\section{$\underline{\text { Surface Examinations }}$}

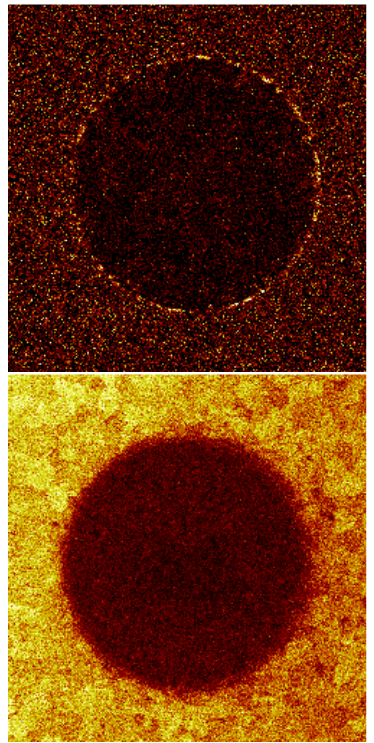

Si

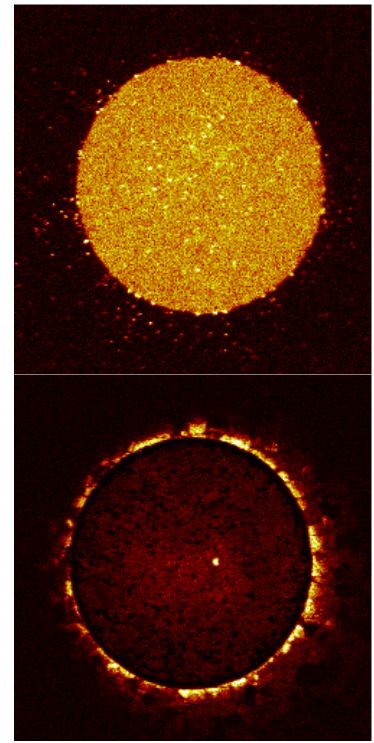

Mn

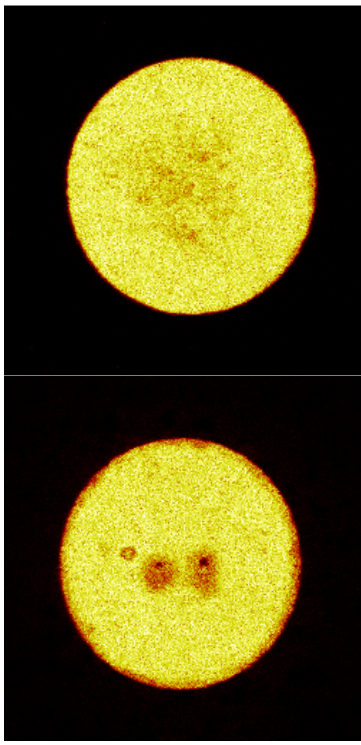

$\mathrm{Sr}$

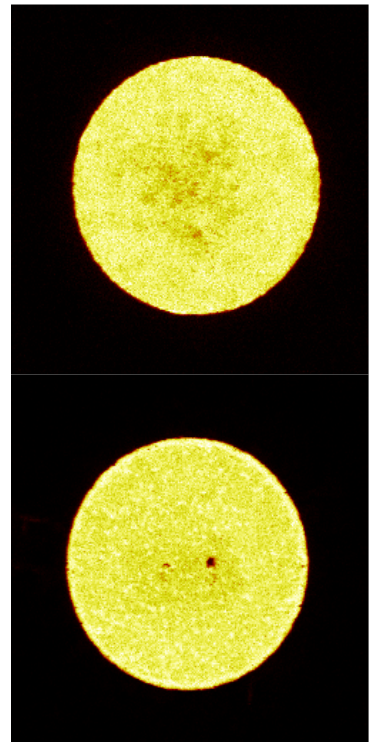

LaO

Figure 8. TOF-SIMS of two $100 \mu \mathrm{m}$ microelectrodes, a not tested reference (upper row) and an electrochemical tested (lower row) for the 4 signals from $\mathrm{Si}, \mathrm{Mn}, \mathrm{Sr}$ and $\mathrm{LaO}$. The lighter, the higher is the signal (the counts) of a given species.

Both reference (not tested) microelectrodes and tested ones were characterized by SEM and TOF-SIMS. The SEM micrograph of Figure 2 is fairly representative, and no clear changes in the electrode appearance was observed by SEM. Figure 8 shows a series of TOF-SIMS micrographs plotted as a function of electrode polarization showing 
qualitatively the distribution of the four elements $\mathrm{Si}$ (impurity), $\mathrm{Mn}, \mathrm{Sr}$ and $\mathrm{La}$ (using the $\mathrm{LaO}$ mass signal). Note the small dot to the right of the center in the three lower right micrographs. This is where the contacting tip was placed.

Figure 8 shows that Sr- and La-oxides segregates to the surface of the LSM during the time of electrochemical testing. Si-oxide (together with alkaline metals - not shown) segregates to the YSZ surface and Mn-oxide segregates to the TPB region. The total picture of segregation of various elements poses a much more complicated picture than shown in Figure 8. A separate publication on this subject is in preparation.

\section{Discussion}

The results of Figures 5 and 7 show that the reaction path of oxygen transfer through the TPB path is the dominant one for the cases in air and pure oxygen and for anodic polarization of $250 \mathrm{mV}$ in $\mathrm{N}_{2}$ with ca. $10^{-4}$ bar $\mathrm{O}_{2}$, which roughly corresponds to the oxygen potential in air. With decreasing oxygen partial pressure, the reaction path through LSM bulk diffusion becomes more and more important, and at $-200 \mathrm{mV}$ polarization in $10^{-4}$ bar $\mathrm{O}_{2}$, corresponding to ca. $10^{-6}$ bar $\mathrm{O}_{2}$, it seems totally dominating. Below ca. $10^{-6}$ bar $\mathrm{O}_{2}$ LSM with 20 to $30 \%$ Sr substitution of La, LSM becomes clearly oxygen deficit, i.e. the oxide vacancy concentration becomes significant (17). This may explain the bulk diffusion and the decrease of $R_{p}$ with increasing cathodic polarization.

The decrease of $R_{p}$ with increasing anodic polarization is surprising in this light. A possibility is that the segregations of the type seen in Figure 8 are affected by the anodic polarization in a way that decreases the polarization resistance, in particular in the range up to $+200 \mathrm{mV}$ above which it seems to approach a constant value. (These data are not shown here due to space limitations. They will be submitted together with more data in a full paper to the Journal).

The impedance spectra of the LSM microelectrodes studied in this work consists of at least two arcs, one within a frequency range of $0.01-100 \mathrm{~Hz}$ and the other within a frequency range of $10-10^{4} \mathrm{~Hz}$ varying with test conditions. Sometimes these two frequency regimes contain more than one arc. The order of magnitude of the calculated area-specific capacitance of $100 \mu \mathrm{F} \mathrm{cm}^{-2}$ and $1 \mathrm{mF} \mathrm{cm}^{-2}$ for the high and low frequency arc, respectively, points to the LSM-YSZ interface for the high frequency $\operatorname{arc}(\mathrm{s})$ and changes in the LSM stoichiometry for the low frequency arc. The capacitance associated with oxygen stoichiometry variation in an LSM film is called chemical capacitance. It can be estimated from the oxygen stoichiometry change, $\delta$, with $p \mathrm{O}_{2}(18)$ :

$$
C_{\text {chem }}=\frac{8 F^{2} L}{R T V_{m}} \frac{d \delta}{d \ln p O_{2}}
$$

in which $F$ is the Faraday constant, $L$ is the thickness of the film and $V_{m}$ is the molar volume of LSM. By differentiating the Nernst equation, the following can be obtained:

$$
d E=\frac{R T}{4 F} d \ln \left(p O_{2}\right)
$$


By combining Eq. [1] and [2], the chemical capacitance can be expressed as:

$$
C_{\text {chem }}=\frac{2 F L}{V_{m}} \frac{d \delta}{d E}
$$

The value of $d \delta / d E$ for LSM at $1000{ }^{\circ} \mathrm{C}$ was measured by Zachau-Christiansen et al. (19). Based on their measured values for $\left(\mathrm{La}_{0.75} \mathrm{Sr}_{0.25}\right)_{0.95} \mathrm{MnO}_{3}$ and Eq. [3], $C_{\text {chem }}$ was calculated to around $10 \mathrm{mF} \mathrm{cm}$, which, considering the difference in temperature, is similar to the value determined from impedance $\left(1 \mathrm{mF} \mathrm{cm}^{-2}\right)$ supporting the assignment of the low frequency arc to changes in LSM stoichiometry.

Thus, the high frequency arc is assigned to transfer of oxide ions across the LSM/YSZ interface near the TPB at high $p \mathrm{O}_{2}$ or high anodic overpotential, while the low frequency arc is assigned to changes in the LSM film associated with the polarization, which in turn is associated with the oxygen exchange between gas phase and LSM.

Takeda et al. (14) found $R_{p} \approx 10^{3} \Omega \mathrm{cm}^{2}$ at $800{ }^{\circ} \mathrm{C}$ in air and activation energy of 1.87 $\mathrm{eV}$ for large circular $\mathrm{La}_{0.7} \mathrm{Sr}_{0.3} \mathrm{MnO}_{3}$ thin film electrodes with $12 \mathrm{~mm}$ diameter and $2 \mu \mathrm{m}$ thickness. Their electrodes were sintered for $5 \mathrm{~h}$ at $800{ }^{\circ} \mathrm{C}$ before test at the same temperature. If their $R_{p}$ is recalculated to line specific resistance instead it gives ca. 3.3 $\cdot 10^{3} \Omega \mathrm{cm}$ compared to ca. $4 \cdot 10^{6} \Omega \mathrm{cm}$ at $856^{\circ} \mathrm{C}$ found here for $\left(\mathrm{La}_{0.75} \mathrm{Sr}_{0.25}\right)_{0.95} \mathrm{MnO}_{3}$ annealed for $5 \mathrm{~h}$ at $1000{ }^{\circ} \mathrm{C}$ before test. The considerable difference may be caused by several differences in the preparation and the geometry of the two sets of electrodes.

The absolute values of the slopes of $\log \left(R_{p}\right)$ versus $\log (d)$ determined in the present work are all smaller than those reported by Fleig et al. (2). The difference may be ascribed to different experimental conditions: $856{ }^{\circ} \mathrm{C}$ versus $800{ }^{\circ} \mathrm{C}$, the thicknesses of 100 and $250 \mathrm{~nm}$ versus $500 \mathrm{~nm}$ of the LSM microelectrodes and possibly a number of other details that we are not aware of. An important question is how sensitive the nature of the segregations is with respect to test conditions and time. Recently, it has been shown that the segregations actually are very dependent on temperature and composition (20).

\section{Conclusion}

The influence of oxygen partial pressure and polarization on the electrical characteristics of LSM microelectrodes was investigated. Circular LSM microelectrodes with a nominal composition of $\left(\mathrm{La}_{0.75} \mathrm{Sr}_{0.25}\right)_{0.95} \mathrm{MnO}_{3}$ were prepared on polished 8YSZ pellets. The electrochemical measurements were carried out using a CAHT-SPM set-up for contacting the electrodes and for impedance and $\mathrm{i}-\mathrm{V}$ measurements at different temperatures in air, $\mathrm{N}_{2}$ with $p \mathrm{O}_{2} \approx 10^{-4}$ bar and pure oxygen. Under OCV, the polarization resistance of the LSM microelectrodes scales with the inverse of the microelectrode diameter in air and pure oxygen, while in $\mathrm{N}_{2}$ with $p \mathrm{O}_{2} \approx 10^{-4}$ bar it scales more with the inverse of the electrode area though only completely at cathodic polarization corresponding to $\mathrm{pO}_{2}=10^{-6}$ bar or lower. 


\section{Acknowledgments}

This work was supported financially by The Program Commission on Sustainable Energy and Environment, The Danish Council for Strategic Research, via the Strategic Electrochemistry Research Center (SERC) (www.serc.dk), contract no. 2104-06-0011.

\section{References}

1. V. Brichzin, J. Fleig, H.-U. Habermeier, G. Cristiani and J. Maier, Solid State Ionics, 152-153, 499 (2002).

2. J. Fleig, H.-R. Kim, J. Jamnik and J. Maier, Fuel Cells, 08, 330 (2008).

3. G. J. La O', B. Yildiz, S. McEuen and Y. Shao-Horn, J. Electrochem. Soc., 154, B427 (2007).

4. G. J. la O' and Y. Shao-Horn, Electrochem. Solid-State Lett., 12, B82 (2009).

5. C. Mack, Fundamental Principles of Optical Lithography: The Science of Microfabrication, Wiley, 2007.

6. K. V. Hansen, Y. Wu, T. Jacobsen, M. B. Mogensen and L. Theil Kuhn, Rev. Sci. Instrum., accepted (2013).

7. Y. Wu, K. V. Hansen, T. Jacobsen and M. Mogensen, Solid State Ionics, 197, 32 (2011).

8. A. K. Optiz and J. Fleig, Solid State Ionics, 181, 684 (2010).

9. J. Newman, J. Electrochem. Soc., 113, 501 (1966).

10. R. Holm, Electric Contacts Handbook, 4th ed. Springer Verlag, Berlin, 1958.

11. T. Ishihara, N.M. Sammes and O. Yamamoto, in: High-Temperature Solid Oxide Fuel Cells: Fundamentals, Design and Applications, Eds. S.C. Singhal and K. Kendall, Elsevier, 2003, pp. 83-117.

12. J.A. Kilner and B.C.H. Steele, in: Nonstoichiometric oxides, Ed. O.T. Sørensen, Academic Press, London, 1981, pp. 233-269.

13. C.C. Appel, N. Bonanos, A. Horsewell and S. Linderoth, J. Mater. Sci., 36, 4493 (2001).

14. Y. Takeda, R. Kanno, M. Noda, Y. Tomida and O. Yamamoto, J. Electrochem. Soc., 134, 2656 (1987).

15. E. Siebert, A. Hammouche and M. Kleitz, Electrochim. Acta, 40, 1741 (1995).

16. E. J. L. Schouler and M. Kleitz, J. Electrochem. Soc, 134, 1045 (1987).

17. J. Mizusaki, N. Mori, H. Takai, Y. Yonemura, H. Minamiue, H. Tagawa, M. Dokiya, H. Inaba, K. Naraya, T. Sasamoto and T. Hashimoto, Solid State Ionics, 129, 163 (2000).

18. W. Jung and H. L. Tuller, J. Electrochem. Soc., 155, B1194 (2008).

19. B. Zachau-Christiansen, T. Jacobsen, K. West and S. Skaarup, in: Proceedings of the 14th Ris $\phi$ International Symposium on Materials Science: High temperature Electrochemical Behavior of Fast Ion and Mixed Conductors, Eds. F.W. Poulsen, J.J. Bentzen, T. Jacobsen, E. Skou and M.J.L. Østergård, Ris $\varnothing$ National Laboratory, Roskilde, Denmark, 1993, pp. 487-494.

20. W. Lee, J.W. Han, Y. Chen, Z. Cai and B. Yildiz, J. Am. Chem. Soc., 135, 7909 (2013). 